\title{
K-Wire Fixation of Proximal Three Part Humerus Fractures - An Everlasting Result Oriented Technique
}

\author{
Amber Varyani ${ }^{1}$
}

${ }^{1}$ Department of Orthopaedics, Government Medical College, Kannauj, Uttar Pradesh, India.

\section{ABSTRACT}

\section{BACKGROUND}

Proximal humerus $\left(3^{\text {rd }}\right)$ part fractures have always been posing great challenges to the orthopaedicians, due to extreme complexity involved in it, mainly, deformed muscular forces around fracture site, osteoporosis and non-affordability to new generation plates and screws etc. Ever since the inception of internal fixation, different approaches have been used, for proximal humerus (3rd) part fractures, like fixation with anatomically contoured locking plates with locking screws and nonlocking plates, hemi-arthroplasty, percutaneous k-wire etc. but only little had been compiled and recorded on such fractures. This study was conducted to evaluate and determine the efficacy of K-wire fixation in such fractures with supporting data to draw a clear-cut favourable conclusion over other methods of fixation of such fractures.

\section{METHODS}

20 patients were included (matching our inclusion criteria), rest were treated differently and were excluded from the study. All fractures were classified in accordance with Neer classification. All patients were treated with K-wire fixation; only the number of K-wires differed from case to case. After their discharge from hospital, all patients were called for stringent review for 15, 30, 60, 90 days on half yearly and yearly basis. Final outcome was evaluated using constant Murley score.

\section{RESULTS}

The average union time was 22 weeks; the mean constant Murley's score was 82 points. Only 3 post-operative complications were noted among all the 20 patients; these were, one mal-union and two cases of pin tract infection. Result was overwhelming success for us. The results of our study were extremely encouraging and in favour of K-wire fixation of such fractures.

\section{CONCLUSIONS}

K-wire fixation of proximal humerus [3rd part] fractures provide stable fixation of such fractures, with negligible post-operative complications and at an extremely cheap cost, easily affordable to average and low-income group patients with early discharge from the hospital, with very low intra operative blood loss and very low operative time, and exposure to C-arm machine.

\section{KEY WORDS}

Proximal Humerus [3 $\left.{ }^{\text {rd }}\right]$ Part Fracture, Percutaneous K-Wire Fixation, Neer Classification, Greater Tuberosity
Corresponding Author: Dr. Amber Varyani, 122/455, Shastri Nagar, Near Kali Mathiya Mandir, Kanpur, Uttar Pradesh, India.

E-mail: amber_varyani2000@yahoo.com

DOI: $10.14260 /$ jemds/2021/111

How to Cite This Article:

Varyani A. $K$ - wire fixation of proximal three part humerus fractures - an everlasting result oriented technique. J Evolution Med Dent Sci 2021;10(08):511514, DOI: $10.14260 /$ jemds/2021/111

Submission 17-09-2019,

Peer Review 15-07-2020,

Acceptance 21-07-2020,

Published 22-02-2021.

Copyright (C) 2021 JEMDS. This is an open access article distributed under Creative Commons Attribution License [Attribution 4.0 International (CC BY 4.0)] 


\section{BACKGROUND}

Proximal humerus $\left(3^{\text {rd }}\right)$ part fractures have always posed great challenges to the orthopaedic fraternity, even before the inception of surgical intervention and also after it. The main reasons being, deformed muscular forces around the fracture site., ${ }^{1}$ osteoporosis is elderly patients., ${ }^{2}$ non-affordability to new generation locking plates \& screws (most intricate problem faced by majority of orthopaedicians). The fractures were classified in accordance with Neer classification criteria, ${ }^{3}$ i.e., in non-displaced fractures, conservative treatment to be followed, and only in those fractures where displaced fragment had an angulation of articular surface $<45^{\circ}$ and displacement of major segments was $<1 \mathrm{~cm}$, surgical intervention needed to be done in accordance with Neer classification. All patients who fell under the category of conservative treatment, their arms were immobilized by POP (plaster of Paris) with arm sling. All the patients who fell under the category of surgical intervention in accordance with Neer classification were further tested with inclusion criteria and exclusion criteria, the excluded patients were treated by different surgical techniques. The included patients were treated with percutaneous K-wire fixation with (CRIF), closed reduction internal fixation. ${ }^{4}$ Fresh $\mathrm{x}$-rays were done and reviewed and surgeries were planned accordingly.

In the present day commonly and frequently used surgical techniques includes, percutaneous K-wire fixation, intra medullary humeral nails, pins, compression plates and screws, anatomically contoured special locking plates and screws (L.P.H.P, PHILOS), 5,6 and hemi-arthoplasty ${ }^{7,8}$ etc. But only little had been compiled and recorded on such fractures and we expect some big studies to be done for favourability of plates on such fractures, but among all, K-wire fixation provides, stable fixation of the fractures, with low blood loss, less invasive, easily affordable to the poor and medium income group patients. The main aim of our study was to determine and establish the efficacy of K-wire fixation of such fractures. Though our results were highly encouraging and positive, but a more elaborate study shall be done on higher number of patients, for clear conclusion of "Equality if not Superiority" of result of K-wire fixation on such fractures as compared to other surgical techniques used for fixation of such fractures, which are on a higher cost side and beyond the reach of common masses. Though our study was on a smaller group of patients, its results were convincingly favouring " K-wire fixation of proximal humerus $3^{\text {rd }}$ part fractures". The K-wire fixation is affordable to all income groups and even to the poor masses. Thus K-wire fixation of proximal three-part humerus fractures, provides a comprehensive stable treatment in such fractures to all the patients at very low cost and in a very less invasive way.

The results of this study were so encouraging that we are driven to do a large study on higher number of patients so as to draw a conspicuous conclusion in favour of $\mathrm{K}$-wire fixation of such fractures, and also some large comparative studies should be carried out to establish the superiority of K-wire fixation over open or closed plate fixation of such fractures.

\section{METHODS}

A prospective intervention study was carried out in our institution, Government Medical College Kannauj for 2 years from July 2017 to June 2019 and on total 20 patients with proximal humerus [ $3^{\text {rd }}$ part] fractures.

All 20 patients were treated with CRIF with percutaneous $\mathrm{K}$-wire fixation (closed reduction internal fixation). The sample size was taken based on the convenience of the study. The mean constant Murley score was 81 (83:102) in the final outcome. ${ }^{9}$

\section{Inclusion Criteria}

1. Patients with proximal humerus [3 part] fractures.

2. Patients with either gender with age group ranging between 20 to 75 years.

3. Patients with fracture which was not older than 5 days.

\section{Exclusion Criteria}

1. Patients with open wound fractures or patients with poly fracture.

2. Patients already undergone surgery, requiring revision surgery.

3. Patients with pathological fractures.

4. Patients with history of chronic illness.

All the proximal humerus fractures met the criteria in accordance with Neer classification ${ }^{5}$ i.e. an angulation of articular surface $<45^{0} \&$ displacement between major fragments $<1 \mathrm{~cm}$ or fractures with valgus impaction. Preoperative $\mathrm{x}$-ray, anteroposterior (AP), lateral, were done and reviewed and the surgeries were planned accordingly. ${ }^{10}$

\section{Operative Technique}

A block was given to patients; patients' upper part was risen to $50^{\circ}$ by tilting the table. 98 to $100 \%$ reduction was achieved in all patients by traction, manipulation and arm abduction. 4 to $6 \mathrm{~K}$-wires were used under image intensifier. K-wires were inserted to the desired position, avoiding injury to radial nerve, axillary nerve etc. The K-wires were bent near the skin, to avoid migration.

The mean operative time was 45 minutes [30 to 60 minutes], the average blood loss was $45 \mathrm{ml}$ [30 to $60 \mathrm{ml}$ ]. Patients were administered with intravenous antibiotics for 3 days post operatively and active shoulder movement exercises were deliberately delayed and started 5 to 6 weeks post operatively. All the patients were followed up in OPD at 15 days after operation, then monthly, 6 monthly \& on yearly basis; each time an $\mathrm{x}$-ray (AP, lateral) was done to access the development.

\section{Statistical Analysis}

The Statistical Package for Social Science \{SPSS Version 20 was used for data analysis. Mean, median and SD were used to describe quantitative data. Qualitative data were summarized using frequency and percentage. 
RESULTS

All fractures got united with average union time of 22 weeks [18 to 26 weeks] with standard deviation of 3 weeks. Postoperative complications were noticed in total 03 patients, 02 patients had pin tract infections and one patients had malunion. The patients with pin tract infection were treated with antibiotics (oral as well as intravenous) and daily dressing, and by rigorous monitoring and were discharged after symptoms of infections had disappeared completely. The patients with mal-union had acceptable level of movements, so he was not given any further surgical intervention. The mean constant Murley score was 81 . In final follow up with standard deviation of 05 . The results of our study were highly encouraging \& highly conclusive in favour of K-wire fixation of such fractures, due to low cost, minimal blood loss and early discharge from hospital in addition to providing stable fixations.

\begin{tabular}{|ccccc|}
\hline Non-union & Malunion & Infection & Misc. & $\begin{array}{c}\text { Average } \\
\text { Murley Score }\end{array}$ \\
\hline NIL & 1 & 2 & NIL & 81 \\
\hline \multicolumn{4}{|c|}{ Table 1. Post-Operative Complications } \\
\hline
\end{tabular}

\section{DISCUSSION}

It has always been very hard for orthopaedicians to select the fixation procedure for fractures of $3^{\text {rd }}$ part humerus, taking into consideration the age, cost, time of stay, stability and ultimately the result of that procedure. Though the surgical advancement in treating proximal humerus fractures [ $3^{\text {rd }}$ part] cannot be ignored or underestimated but the percutaneous Kwire fixation of such fracture has been the evergreen resultoriented approach since its inception. This technique has always been providing good results with extremely low postoperative complications and has been successfully used in our study on all age groups, osteoporotic patients with low blood loss and short post-operative stay in hospital. Besides being less invasive, it provides higher stability to these fracture and a final outcome has been better than desired. The K-wire fixation of such fracture is extremely cost effective and in the reach of the poorest candidate. Though the rehabilitation and physiotherapy exercises are being delayed in K-wire fixation, but the ultimate results are so promising that it decimates such delay in start of exercises. Calvo E de Miguel $\mathrm{I}^{11}$ had got promising results [88 \%] in fixation of proximal humerus [3 part] fractures with percutaneous K-wire fixation though it has been indicated by some authors that anatomical reduction of greater tuberosity is directly proportional to the final outcome of surgery, and they indicate open reduction of such fractures to achieve total reduction of greater tuberosity (ORIF) (open reduction and internal fixation) but in our study best reduction of greater tuberosity was achieved by traction, manipulation and abduction without requiring any open intervention for that, it has been the great achievement in our study. This makes the K-wire fixation as best technique for such fractures. In our study, all fractures were reduced conservatively, without requiring any invasion, thus making it extremely less invasive with extremely low chances of postoperative infection. Some surgeons prefer open reduction and then fixation with K-wire of such fractures, but this doesn't serve the original purpose. Best results of K-wire fixation of such fractures can be only achieved by conservative reduction by traction, manipulation and abduction and then fixation with K-wire. This helps in extremely low post-operative complications and provides stable fixation of such fractures. If open reduction is inevitable, then both anatomically contoured plate and $\mathrm{K}$ - wires serve the same purpose and give nearly same results. The K-wire fixation of such fractures should be done in closed reduction, for getting desired results. Our study had proved the efficacy of K-wire fixation (CRIF), but results start to alter if open reduction is done. Best part in our study was that we had used K-wires in all the 20 patients irrespective of their ages, sex, osteoporosis, extreme displacements of fracture site, etc and achieved extremely encouraging results intra-operatively as well as postoperatively. Thus, we can draw a clear-cut conclusion of supremacy of K-wire fixation (CRIF) (closed reduction and internal fixation) of such fractures. We wish that such studies shall be carried out on fairly large number of patients, and also some big comparative studies be carried out to clearly make conclusions in favour of K-wire fixation of these fractures.

\section{CONCLUSIONS}

Percutaneous K-wire fixation gives stable fixation of proximal humerus [3 part] fracture with extremely low post-operative complications, at an extremely low cost, being affordable by poorest candidates. The final outcome and cost effectiveness of K-wire fixation has been extremely remarkable. The delaying of physiotherapy gets decimated by the final outcome of K-wire fixations. So, we can conclude that K-wire fixation of $3^{\text {rd }}$ part humerus fractures provide extremely good postoperative results.

Data sharing statement provided by the authors is available with the full text of this article at jemds.com.

Financial or other competing interests: None.

Disclosure forms provided by the authors are available with the full text of this article at jemds.com.

\section{REFERENCES}

[1] Sturzenegger M, Fornaro E, Jakob RP. Results of surgical treatment of multifragmented fractures of the humeral head. Arch Orthop Trauma Surg 1982;100(4):249-59.

[2] Paavolainen P, Bjorkenheim JM, Slatis P, et al. Operative treatment of severe proximal humeral fractures. Acta Orthop Scand 1983;54(3):374-9.

[3] Neer CS. Displaced proximal humeral fractures. II. Treatment of three-part and four-art displacement. J Bone Joint Surg Am 1970;52(6):1090-103.

[4] Esser RD. Open reduction and internal fixation of threeand four-part fractures of the proximal humerus. Clin Orthop Relat Res 1994;299:244-51.

[5] Einarsson F. Fractures of the upper end of the humerus: discussion based on the follow-up of 302 cases. Acta Orthop Scand Suppl 1958;32:1-215. 
[6] Cheng JC, Ng BK, Ying SY, et al. A 10-year study of the changes in the pattern and treatment of 6,493 fractures. J Pediatr Orthop 1999;19(3):344-50.

[7] Tanner MW, Cofield RH. Prosthetic arthroplasty for fractures and fracture-dislocations of the proximal humerus. Clin Orthop Relat Res 1983;179:116-28.

[8] Ligier JN, Metaizeau JP, Prevot J, et al. Elastic stable intramedullary pinning of long bone shaft fractures in children. Z Kinderchir 1985;40(4):209-12.

[9] Willems WJ, Lim TE. Neer arthroplasty for humeral fracture. Acta Orthop Scand 1985;56(5):394-5.
[10] Mcllveen SJ, Neer CS. Recent results and technique of prosthetic replacement for four part proximal humeral fractures. AAOS 53rd Annual Meeting Final Program 1986: p. 107.

[11] Calvo E, de Miguel I, de la Cruz JJ, et al. Percutaneous fixation of displaced proximal humeral fractures: indications based on the correlation between clinical and radiographic results. J Shoulder Elbow Surg 2007;16(6):774 - 81. 